\title{
Differential Modulation of Circulating Endothelial Progenitor Cells in Peripheral Blood Monocyte Population of an Early Stage of Streptozotocin-Induced Diabetic Retinopathy
}

\author{
Muthaian Rupadevi and Ramasamy Raveendran \\ Department of Pharmacology, Jawaharlal Institute of Postgraduate Medical Education and Research (JIPMER), Pondicherry, INDIA.
}

\begin{abstract}
Objective: To enumerate the circulating endothelial progenitor cells (EPCs) in peripheral blood mononuclear cells (PBMC) in streptozotocin (STZ) induced diabetic retinopathy (DR) rat model. Materials and Methods: Retinal microvascular complications in STZ induced diabetic Wistar rats were validated after 4 months using trypsin digestion assay of retinal vasculature, histological analysis of retina, glial fibrillary acidic protein (GFAP) immunostaining. Subsequently, circulating EPCs were quantified in PBMCs from diabetes induced rats after 4 months using markers such as CD-34, CD-31, CD-146, VE-Cadherin and Flk-1 by flow cytometry. Results: Pericyte loss, acellular capillaries, retinal layer thickness, microglial activation and increased nitric oxide (NO) levels were observed after 4 months of diabetes induction. Whereas the EPC markers. While the EPC markers such as CD-34, CD-31, VE-Cadherin were decreased, the Flk-1+ve cells were up-regulated in the endogenous EPC pool. Conclusion: The quantity of EPCs is modulated in diabetes which may provide an insight into the use of EPCs as a biomarker for the progression of diabetes induced microvascular complication.
\end{abstract}

Key words: Diabetic retinopathy, Endothelial progenitor cells, FIK-1, GFAP, Streptozotocin.

\section{PICTORIAL ABSTRACT}

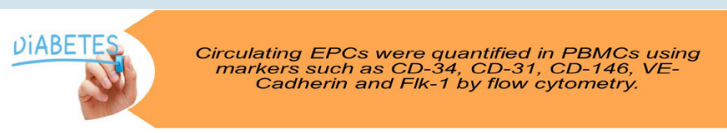

The EPC markers such as CD-34, CD-31, VE-
Cadherin were 1 ,
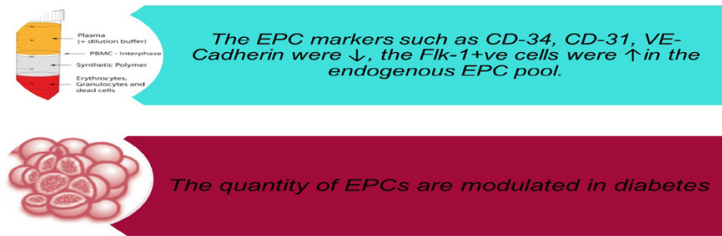

Correspondence :

Dr. Ramasamy Raveendran,

Department of Pharmacology, Jawaharlal Institute of Postgraduate Medical Education and Research (JIPMER), Pondicherry, INDIA. Phone no: 91-94421 73134;

E-mail: dr.ravee@gmail.com

DOI: 10.5530/jyp.2016.3.6

\section{INTRODUCTION}

Diabetic retinopathy (DR) has become pre-eminent cause of acquired blindness in working adults in industrialized countries. The manifestation of DR causes visual impairment due to the development of diabetic macular edema and/or proliferative DR. The worldwide prevalence of DR is speculated to increase from 126.6 million to 191 million by $2030 .{ }^{1}$ Several therapeutic strategies like laser photo-coagulation, intra vitreal corticosteroids, intra vitreal anti-vascular endothelial growth factor (VEGF) agents, vitreo-retinal surgery are available at advanced stage of the disease with significant adverse effects. An insight into inflammatory process during the early stage of DR may shed light on various diagnostic markers and potential therapeutic targets for early intervention of DR before its culmination to complications.

Retinal vessel abnormalities start with progressive thickening and dysfunction of basement membrane with loss of endothelial cells, pericyte and vascular smooth muscle cells. ${ }^{2}$ Progressive capillary non-perfusion induces HIF-1 $\alpha$ derived abnormal neo-vascularization which leads to the reduction of endothelial cell replicative capacity and cells reaching their Hayflick limit. ${ }^{3,4}$

Endothelial progenitor cells (EPCs) play a major role in the maintenance of normal vasculature including retina. In response to signal from injured endothelial cells and retinal ischemia, EPCs were recruited, mobilized and home to ischemic areas in order to assist vascular remodeling and thereby maintaining normal vasculature. ${ }^{5,6}$ Recent evidences support the notion that type 1 and type 2 diabetic patients have diverse number of circulating EPCs. ${ }^{7.8}$ Increasing evidence suggests that circulating EPCs contribute to pathological neo-vascularization in diabetes induced retinal stress. ${ }^{9}$ EPCs have the potential to home to the sites of tissue ischemia and contribute to vascular repair. ${ }^{10}$ But there is a minor consensus on markers to identify these cells. ${ }^{11}$ These circulating EPCs may be derived from bone marrow, ${ }^{12}$ peripheral blood ${ }^{13}$ and vessel wall itself. ${ }^{14}$ Conflicting results have been reported pertaining the level of circulating EPCs in diabetic patients. Using flow cytometric techniques, reduced ${ }^{15}$ increased $^{16}$ or unchanged levels ${ }^{17,18}$ of EPCs have been reported in diabetic patients. EPCs are positive for diverse range of endothelial cell markers like VEGF-R $\mathrm{R}_{2}$, VE-Cadherin (CD144), CD31, CD34 and CD146. Before the clinical use of EPCs as prognostic markers and therapy, consensus among researchers should be established about the characteristic profile of different population of EPCs during different time-course from acute to chronic stages of DR. Thus, in the present study, we aimed to characterize the circulating EPCs derived from peripheral blood mononuclear cells (PBMCs) with different markers in an experimental model of streptozotocin (STZ) induced DR in rats.

\section{MATERIALS \& METHODS}

\section{Animals}

Male Wistar rats weighing 220-250 g were used for this study. The animals were individually acclimatized and fed a standard commercial diet and water ad libitum for 7 days. The $12 \mathrm{~h} \mathrm{light}$ and $12 \mathrm{~h}$ dark cycle was followed throughout the study period. All the experiments and 
procedures on animals were approved by the Institute Animal Ethics Committee (IAEC) and carried out according to the guidelines of the Committee for the Purpose of Control and Supervision of Experiments on Animals (CPCSEA).

\section{Induction of diabetes mellitus}

Two groups of rats ( $\mathrm{n}=6$ in each group) were used; group 1 (control)received citrate buffer by i.p. and group-2 (diabetic) was challenged with STZ. In brief, STZ (45 mg/kg body weight) in $50 \mathrm{mmol} / \mathrm{l}$ citric acid buffer ( $\mathrm{pH} 4.5$ ) was used to induce diabetes mellitus by a single i.p. injection to the rats that had been fasted for $16 \mathrm{~h}$. Blood glucose was measured prior to and $48 \mathrm{~h}$ after STZ injection using Accu-Chek, Active glucose test strips (Roche Diagnostics India Pvt. Ltd.) Rats with blood glucose greater than $300 \mathrm{mg} / \mathrm{dl}$ were considered diabetic and were used for the study. After 16 weeks, both the groups were euthanized by an overdose of pentobarbital, the eyes were enucleated and processed for histology. From each group, 3 retinae were used for analysis.

\section{Histological analysis}

After 4 months of diabetes induction, the animals were sacrificed. Eyeballs were fixed in the $10 \%$ neutral buffered formalin for $24 \mathrm{~h}$, rehydrated and embedded in paraffin. The paraffin-embedded eye balls sectioned with the thickness of $5 \mu \mathrm{m}$ were stained with hematoxylin and eosin. The retinal layer thickness and the morphology of the ganglion cells were analyzed in each eye.

\section{Retinal trypsin digestion assay}

Enucleated eyes were fixed in $10 \%$ neutral buffered formalin for at least $24 \mathrm{~h}$. Subsequently, the retina was isolated and washed in distilled water overnight and then digested with $3 \%$ trypsin (Difco Trypsin 250) in $0.1 \mathrm{M}$ Tris containing $0.2 \mathrm{M} \mathrm{NaF}$ for $1 \mathrm{~h}$ at $37^{\circ} \mathrm{C}$. After the incubation, the removal of inner limiting membrane and the turbidity of the medium were considered a sign of digestion. Further, the adherent retinal tissue was removed from the vessels by gentle shaking and it was mounted on a glass slide for drying. The dried vessels were stained with periodic acidSchiff (PAS) and hematoxylin. ${ }^{19}$

\section{Immunohistochemistry staining with glial fibrillary acidic protein (GFAP)}

After 4 months of diabetes induction, the eyes were enucleated and fixed in $4 \%$ paraformaldehyde (Sigma-Aldrich, St Louis, MO) in a phosphate buffer for $4 \mathrm{~h}$. Three different concentrations of sucrose solution $(10 \%$, $20 \%$ and $30 \%$ overnight) were used for cryoprotection and embedded in resin. Tissue sections $(8 \mu \mathrm{m})$ were obtained on polylysine-treated glass slides. Briefly, retinal sections were blocked with 5\% goat serum, 3\% BSA and $0.25 \%$ Triton $X-100$, and then incubated with a primary monoclonal anti-mouse anti-GFAP antibody (Santa Cruz Biotechnology, Santa Cruz, CA) (1:300 dilution) and counterstained with 4',6-diamidino-2-phenylindole (DAPI) to show the nuclei of retinal cells. The tissue sections were observed under microscope.

\section{Measurement of nitric oxide (NO)}

$\mathrm{NO}$ was determined by measuring the reduction of nitrate $\left(\mathrm{NO}_{3}^{-}\right)$to nitrite $\left(\mathrm{NO}_{2}^{-}\right)$by nitrate reductase followed by colorimetric griess reaction using a colorimetric assay kit (Sigma) in plasma samples. The two experimental groups $(n=6)$; control and diabetic, were assayed simultaneously as per the manufacturer's instruction.

\section{Isolation of PBMCs}

Blood samples $(2 \mathrm{~mL})$ were collected from retro-orbital venous plexus from each rat after 4 months of diabetes induction. All samples in a group were pooled and diluted with phosphate-buffered saline (PBS). PBMCs were isolated by density-gradient centrifugation using FicollPaque Plus (GE healthcare). Isolated cells were washed with PBS and resuspended in PBS supplemented with $0.5 \%$ of bovine serum albumin and $2 \mathrm{mM}$ of EDTA. Non-viable cells were identified by staining with trypan blue and cell viability was calculated using the total cell count and the count of non-viable cells. PBMCs were used for further analysis. All experiments were done in triplicate.

\section{Flow cytometry analysis of monocyte population}

To determine rat EPC subtypes, surface markers for EPCs on circulating PBMCs were analyzed by a flow cytometer (FACS caliber, Becton-Dickinson, San Jose, CA) using CD-31 (Abcam, Cambridge, MA), CD-34 (Santa Cruz Biotechnology, Santa Cruz, CA), CD-146 (Santa Cruz Biotechnology, Santa Cruz, CA), Flk-1 (Abcam, Cambridge, MA) and VE-cadherin (Abcam, Cambridge, MA) antibody. Percentage of cells were analyzed using cellquest software and relative cell numbers were analyzed using FlowJo software.

\section{Data analysis}

Data are given as mean \pm standard error. The nitrite and nitrate levels of both the groups were compared using unpaired t test. A value of $P<0.05$ was considered statistically significant. Statistical analysis was performed using SPSS for Windows version 19.0 (SPSS Inc, Chicago, IL).

\section{RESULTS}

\section{Retinal trypsin digestion assay}

Morphological analysis of retinal vasculature was performed to determine the magnitude of pericyte loss in retinal vasculature following PAS and hematoxylin staining. No defects were observed in control rat retinal vasculature (Figure $1 \mathrm{a}$ and $1 \mathrm{~b}$ ). The loss of pericytes also known as pericyte ghost were observed in diabetic rats which is shown in Figure 1c and 1d. Further, microvascular abnormalities like acellularity in capillaries of retinal vasculature were also seen (Figure 1e and 1f).

\section{Histological analysis}

In Figure 2b, diabetic rats show degenerated shrunken ganglion cells with increased inter cellular space in outer nuclear and inner nuclear layer. Discrimination between outer and inner nuclear layer is found to be less when compared to control rats (Figure 2a). In addition, marked destruction of photoreceptor layer and disorganization of retinal layers were evident in diabetic rat retinal sections.

\section{Immunostaining of GFAP in retina}

Glial cell activation in diabetes induced retinal stress was evaluated by expression of GFAP in retinal sections (Figure 3) of diabetic rats. Distribution of astrocytes is uniform and the staining of GFAP is less intense in control rats (Figure 3a) whereas in GFAP stained retinal sections of diabetic rats (Figure $3 \mathrm{~d}$ ), the cell number in different retinal regions were heterogenous and intense in mid-peripheral retina. The nuclei of retinal cells from the same region and the merged images are shown for control $(3 b, 3 c)$ and diabetes (3e, 3f).

\section{Nitrite and nitrate levels}

Figure 4 shows the nitrite levels in diabetic rats $(17.95 \pm 1.616 \mathrm{ng} / \mu \mathrm{l}$; $\mathrm{p}<0.05)$ which was increased significantly when compared to control rats $(5.352 \pm 1.133 \mathrm{ng} / \mu \mathrm{l})$. In the same manner, nitrate levels of diabetes $(11.42 \pm 0.6771 \mathrm{ng} / \mu \mathrm{l} ; \mathrm{p}<0.05)$ were also found to be increased significantly compared to controls $(6.415 \pm 0.3174 \mathrm{ng} / \mu \mathrm{l})$. 


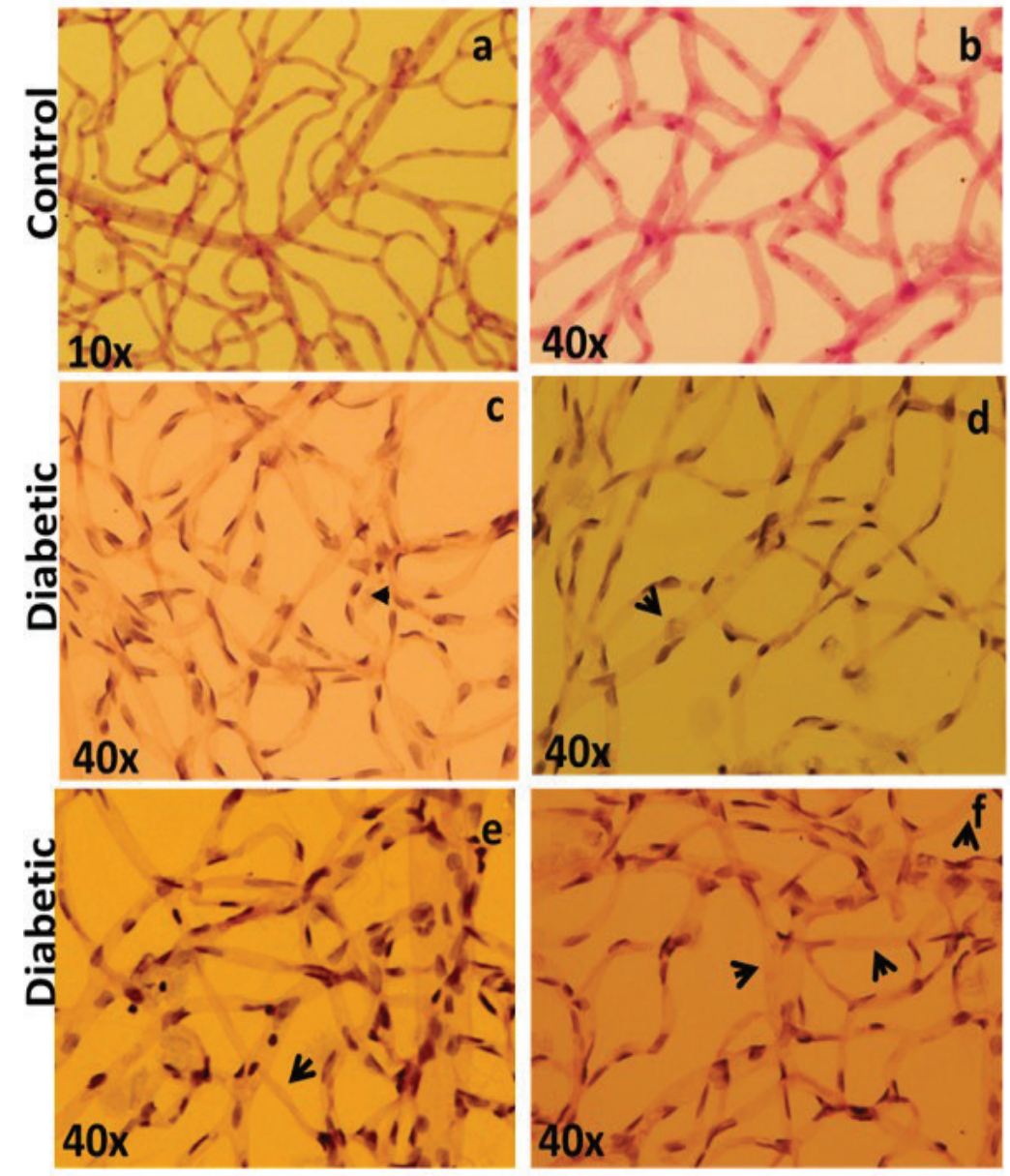

Figure 1: The control and the diabetic rat retinal vasculature stained with PAS and hematoxylin. The arrows indicate the pericyte "Ghost" (1c and 1d) and acellular capillaries (1e and 1f) in the STZ induced diabetic rat.
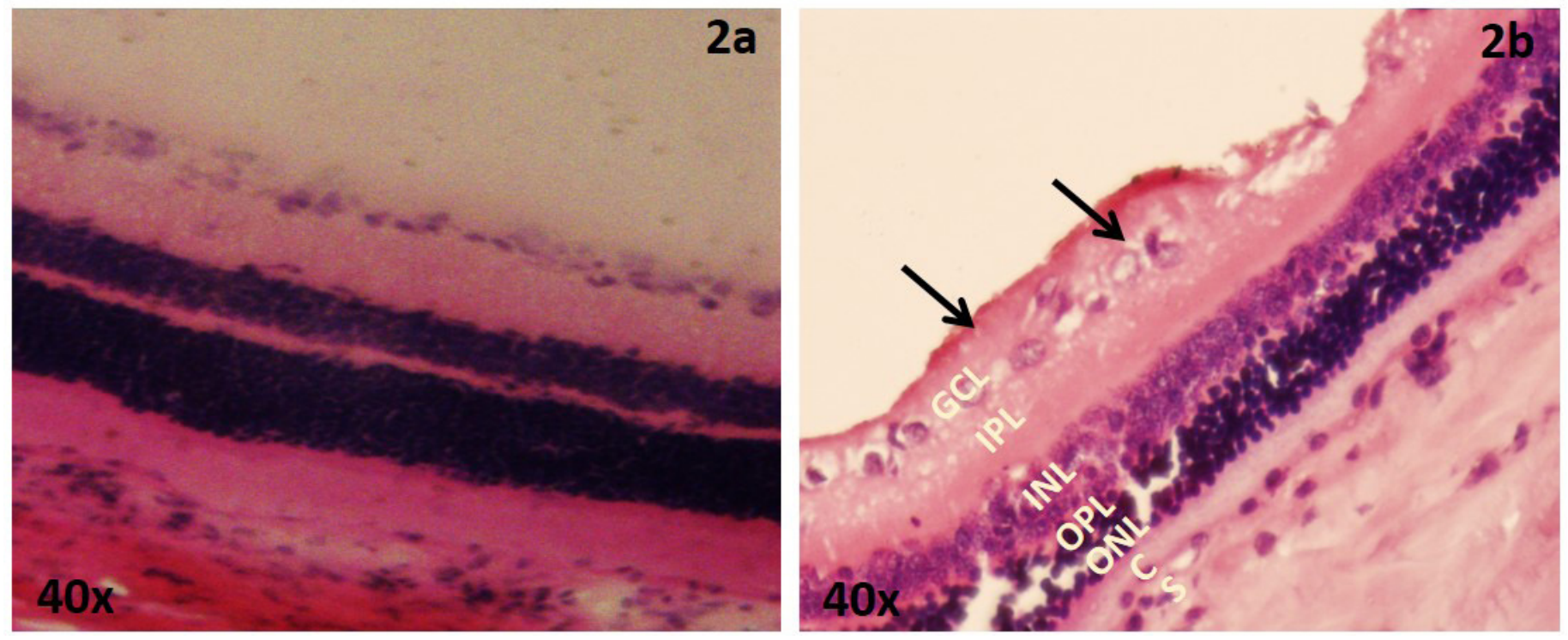

Figure 2: Hematoxylin and eosin stained retinal sections of the control (2a) and the diabetic rat (2b) after 4 months of STZ treatment representing retinal layer thickness and retinal ganglion cell loss. (GCL-Ganglion cell layer; IPL-Inner Plexiform Layer; INL-Inner Nuclear Layer; OPL-Outer Plexiform Layer; ONL-Outer Nuclear Layer; C-Choroid; S-Sclera). 


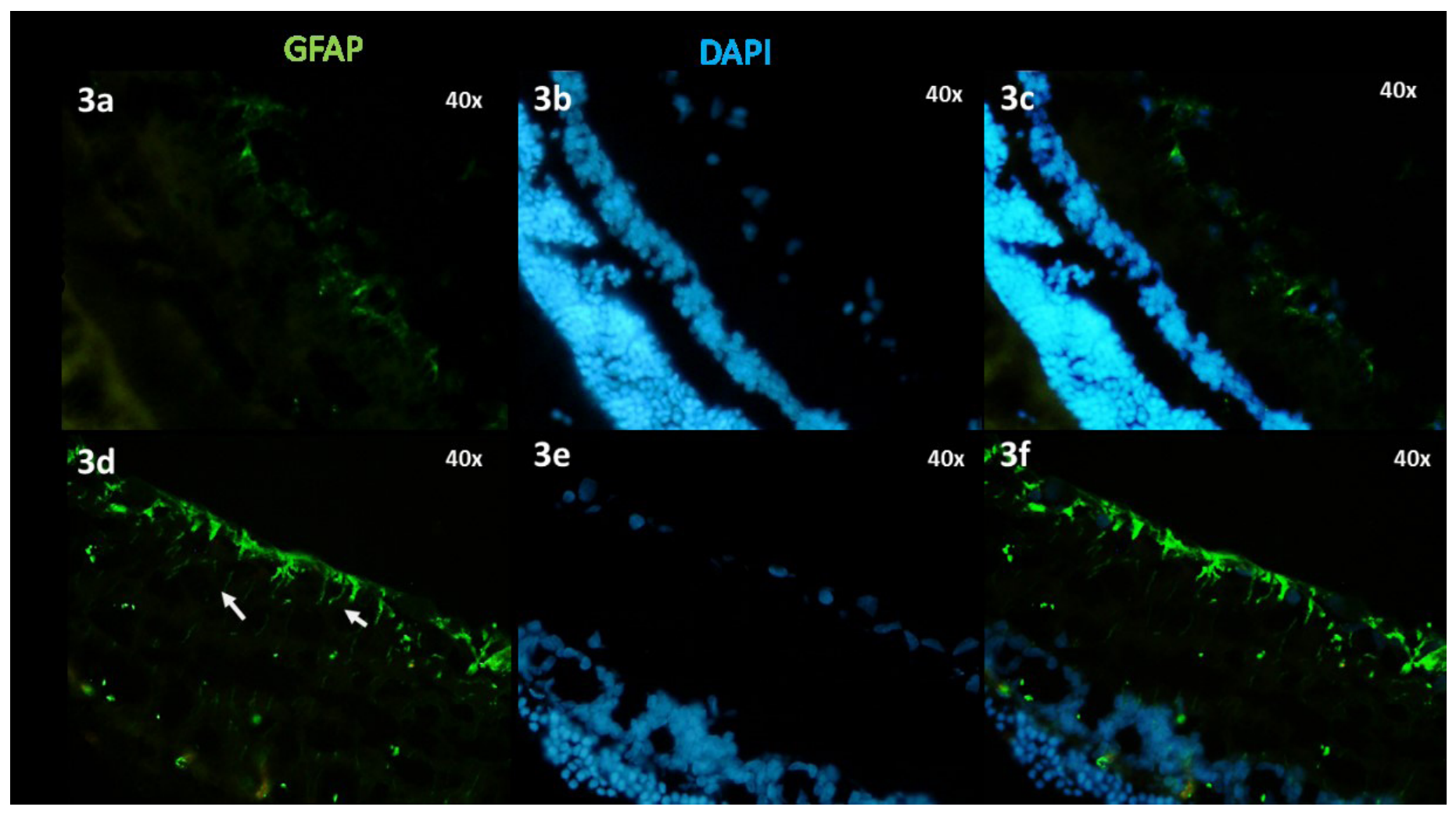

Figure 3: GFAP expression using immunostaining in control (3a) and diabetic (3d) retinal sections counterstained with DAPI (control, 3b and diabetic, 3e) and the merged images (control, $3 \mathrm{c}$ and diabetic, 3f). $3 \mathrm{~d}$ indicates increased GFAP expression in diabetic rats.

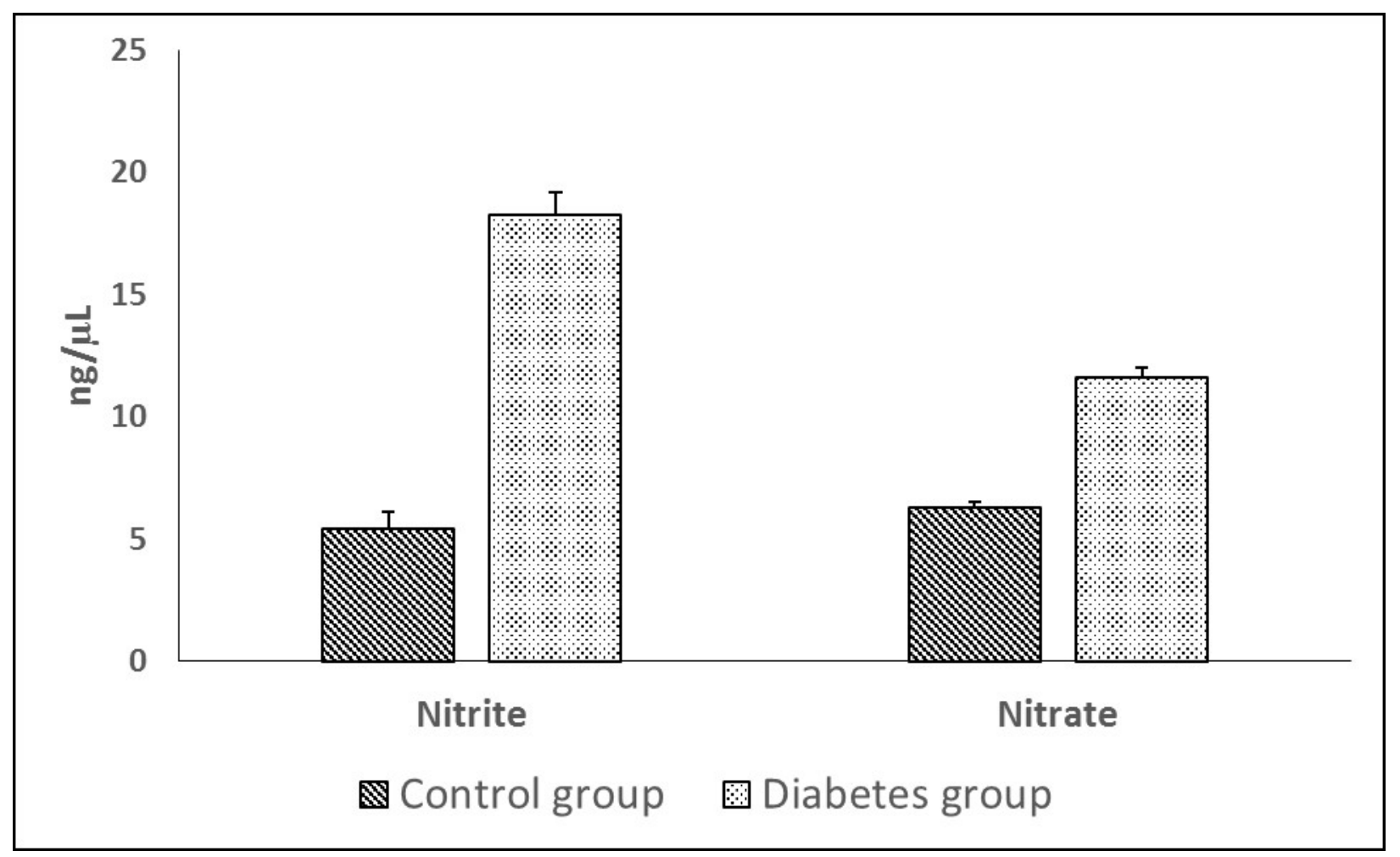

Figure 4: The nitrite and nitrate levels in plasma samples of control and diabetic rat. $n=3$. Data are mean \pm standard error. ${ }^{*} p<0.05$ when compared to respective control. 

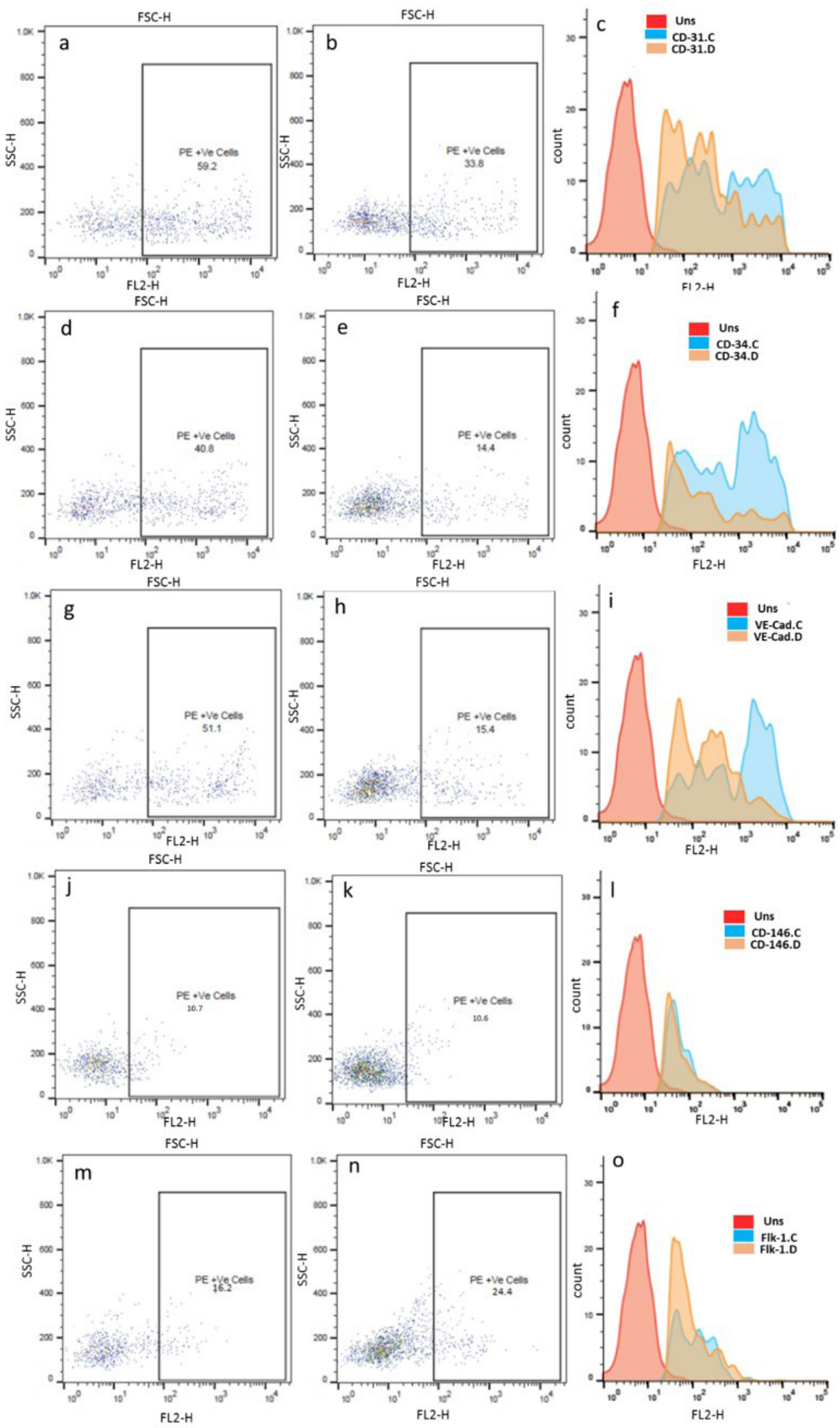

Figure 5: Dot plots for CD-31+ (a,b), CD-34+ (d,e), VE-Cadherin+ $(g, h), C D-146+(j, k)$ and Flk-1+ $(m, n)$ cells showing the monoocyte population in the PBMC of control and diabetic rats. Respective comparative histogram images are given for all the markers. The figures are representative of 3 experiments. 


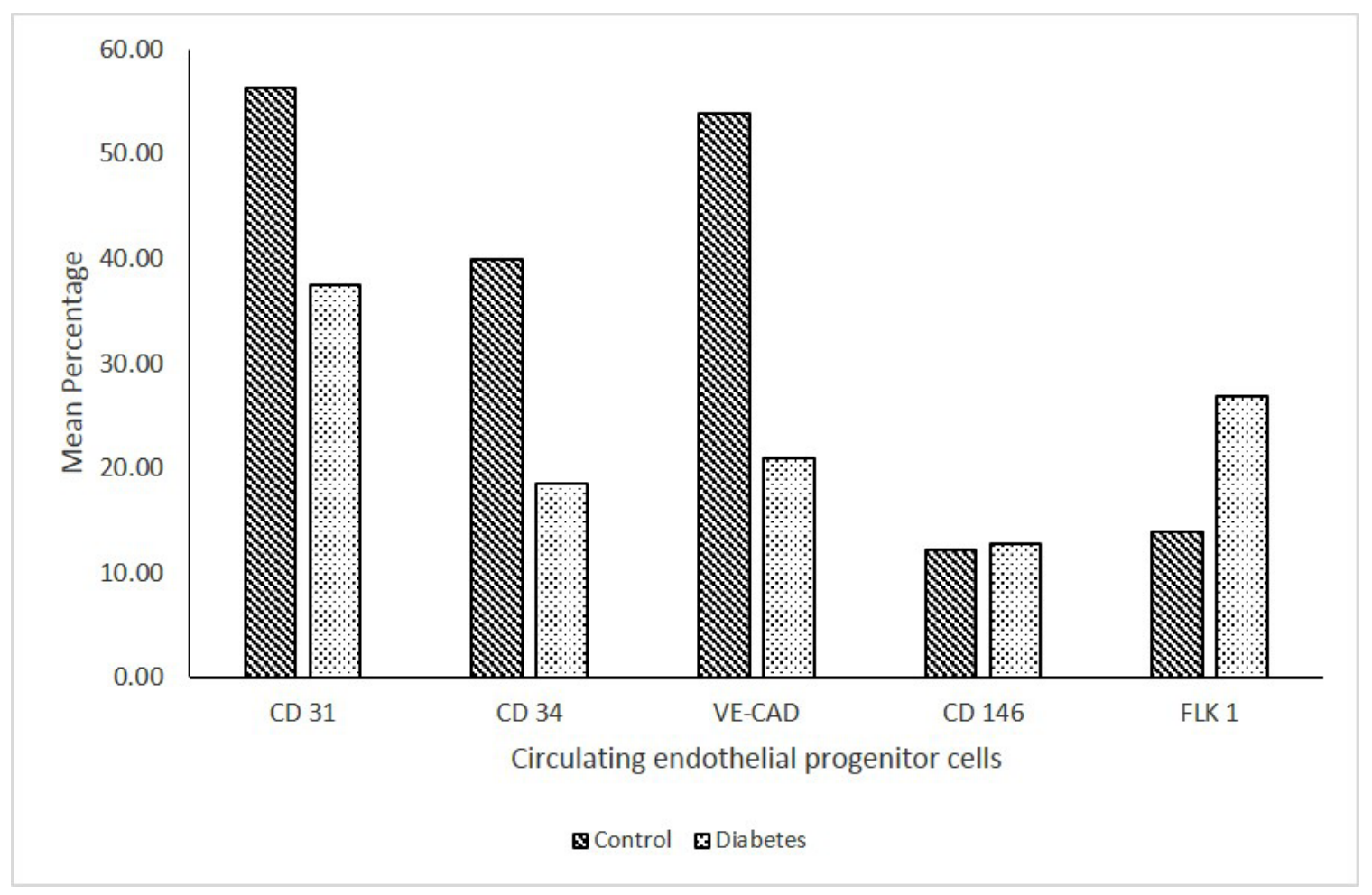

Figure 6: The mean percentage of the EPC markers for both control and diabetic rats. The bars represent the mean percentage.

\section{Immunophenotyping of PBMCs}

Circulating EPC (both early and matured) sub-populations isolated from PBMCs were evaluated by flow cytometric analysis following gating the monocyte sub-population based on forward (FSC) and side (SSC) scatter. Dot plot for CD31 ${ }^{\text {+ve }}, \mathrm{CD} 34^{\text {+ve }}$, VE-Cadherin ${ }^{+v e}, \mathrm{CD} 146^{\text {+ve }}$ and $\mathrm{Flk}^{+\mathrm{ve}}$ sub-population from mononuclear fractions of control rats represented in Figure $5 \mathrm{a}, 5 \mathrm{~d}, 5 \mathrm{~g}, 5 \mathrm{j}$ and $5 \mathrm{~m}$, respectively. Dot plot for $\mathrm{CD} 31^{\text {+ve }}, \mathrm{CD} 34^{+\mathrm{ve}}, \mathrm{VE}-\mathrm{Cadh}{ }^{+\mathrm{rin}}{ }^{+\mathrm{ve}}, \mathrm{CD} 146^{\text {+ve }}$ and $\mathrm{Flk}^{\text {+ve }}$ sub-population of diabetic rats represented in Figure 5b, 5e, 5h, 5k and 5n, respectively. Control and diabetic EPC subpopulations were compared in the respective histograms (Figure 5c, 5f, 5i, $5 \mathrm{l}$ and 5o). Figure 6 shows the mean percentage of CD-31 $1^{\text {ve }}, \mathrm{CD}-34^{\text {+ve }}, \mathrm{VE}-\mathrm{Cadherin}^{+\mathrm{ve}}, \mathrm{CD}-146^{\text {ve }}$ and $\mathrm{Flk}^{\text {+ve }}$ cells in monocytes population of PBMCs. On analyzing the individual EPC positive sub-population, CD- $34^{+v e}, \mathrm{CD}-31^{\text {+ve }}$ and VE-Cadherin ${ }^{\text {+ve }}$ cells were found to be decreased in monocyte population of diabetic rats at 120 days than control PBMC population. Furthermore, there was no change in $\mathrm{CD}-146^{+v e}$ cells compared to control population. A remarkable increase in Flk ${ }^{\text {+ve }}$ cells (VEGF-R2 ${ }^{\text {+ve }}$ ) $(26.9 \%)$ was observed in monocyte population of diabetic rats when compared to PBMCs of control rats (13.93\%).

\section{DISCUSSION}

In the present study, we have validated the early stage of DR in which the circulating $\mathrm{flk}^{+\mathrm{ve}}\left(\mathrm{VEGF}-\mathrm{R} 2^{+\mathrm{ve}}\right.$ ) cells were found to be up-regulated whereas other EPCs (positive for CD-34 ${ }^{+v e}, \mathrm{CD}-31^{+v e}, \mathrm{VE}-$ Cadherin $^{+\mathrm{ve}}$ ) were decreased in PBMC fractions. A few reports suggest that the pathological neovascularization in DR is contributed by high levels of bone marrow derived circulating EPCs. Due to the absence of consensus definition for circulating early and mature EPCs, we investigated the population of monocytes isolated from peripheral blood with several markers such as CD-34, CD-31, CD-146, VE-Cadherin and Flk-1. A previous study has also documented that various cytokines induced the mobilization of co-expressed VEGFR- ${ }^{+} \mathrm{CD} 34^{+}$cells into circulation which are capable of migrating and differentiating into adherent endothelial colonies. ${ }^{20}$ Similarly our study shows that monocyte population of diabetic rats harbors an increased number of Flk $^{+v e}$ cells (VEGF-R2 ${ }^{+v e}$ ) when compared to PBMCs of control rats. The mechanisms that are responsible for the reduced number and impaired function of EPCs in type-2 diabetes mellitus are partially linked to the PI 3-K/Akt/eNOS/NO signalling pathway. ${ }^{21}$

Though the molecular mechanisms behind the BM-derived EPCs recruitment for the vascular tissue repair remain unclear, various reports showed that EPCs play a major role in the vascular repair and new blood vessel formation. In particular, drugs such as statins, erythropoietin, estrogens and vascular endothelial growth factor (VEGF) activate the PI 3-K/Akt pathway leading to the elevation of circulating EPC count, proliferation and migration. ${ }^{22,23}$ Similarly, the compounds that activate PI 3-K/Akt protein kinase pathway also stimulate eNOS. ${ }^{24}$ The expression of eNOS plays an essential role in the stem and progenitor cell mobilization, thus the link between eNOS and the number of EPC is found to be necessary. ${ }^{25}$ Consequently, defects in the PI 3-K/Akt/eNOS/ NO signaling pathway or one of its members may lead to EPC dysfunction.

There are several studies ${ }^{26,27}$ which report the dysfunction of circulating (both early and mature) EPCs in both type 1 and type 2 diabetic patients, but there is a dearth of experimental work exploring the role of circulating EPCs in progressive DR whose clinical feature may manifest as late vasculopathic complications such as peripheral artery disease (PAD) and cardio-vascular disease (CVD). Coronary endothelial dysfunction occurs as a result of shift in the circulating $\mathrm{EPCs}^{28}$ and DR may be attributed to a similar effect.

Though STZ induced diabetic rat model is well established, ${ }^{29,30}$ the timecourse of onset of DR in rat model varies in different studies and remains inconclusive. DR timeline is categorized into non-proliferative (leakage of vessels) and proliferative stage (proliferation of retinal vessels). In the 
current study, the development of progressive DR in diabetic rats were evident by the loss of pericytes, acellular capillaries, decreased retinal layer thickness and increased expression of GFAP in mid-periphery of retina and increased level of inflammatory mediator i.e. nitrite and nitrate levels.

Similar to the present study, Izumi et al. in 2006 reported that the plasma NO levels were found to be significantly increased in patients with diabetes and in any stage of DR. ${ }^{31}$ In addition, the elevated levels of constitutively expressed NOS (nNOS and eNOS) were observed in the retinae of STZ induced diabetic rats associated with retinal vascular permeability. ${ }^{32}$ Hence, a significant increase in nitrite and nitrate levels, one of the key indicators of DR confirms the development of DR in STZ induced diabetic rats in our study.

The functional assays for circulating EPCs in the presence of high glucose levels could unravel the status (impaired or functional) of increased or decreased cells and delineate the mechanism behind the deleterious effect of circulating EPCs leading to abnormal neovascularization in DR. A recent study demonstrated that co-expression of CD $34^{+} / \mathrm{CD} 133^{+} /$ $\mathrm{CD} 09^{+} / \mathrm{CD} 31^{+}$cells is elevated when there is a high risk of proliferative DR. ${ }^{33}$ Hence, the limitations of the current study includes the absence of dual staining of flk ${ }^{+v e}$ cells with CD34 marker which could have strengthened the results of the elevated levels of circulating flk $^{\text {+ve }}$ cells in the diabetes induced rats. These observations may further strengthen the suggestion to use circulating EPCs as a prognostic marker for DR.

\section{CONCLUSON}

In conclusion, our study reports the increased $\mathrm{flk}^{+v e}\left(\mathrm{VEGF}^{+\mathrm{ve}}\right)$ sub-population of circulating EPCs against the background of decreased CD-34 $4^{\text {+ve }}$, $\mathrm{CD}-31^{\text {+ve }}, \mathrm{VE}-\mathrm{Cadherin^{+ve }}$ during the course of progressive DR. Since the actual contribution of increased Flk-1+ve cells to microvascular complications during the early stage of DR is unclear, more studies are warranted to validate further the differential regulation of endogenous EPC pool to provide more insight into the identification of biomarker for the pathogenesis of microvascular complications.

\section{ACKNOWLEDGEMENT}

We acknowledge the Council of Scientific and Industrial Research (CSIR), New Delhi, INDIA, for providing financial assistance in the form of fellowship.

\section{CONFLICT OF INTEREST}

The authors declare no conflict of interest.

\section{ABBREVIATIONS USED}

DR: Diabetic retinopathy; STZ: Streptozotocin; GFAP: Glial fibrillary acidic protein; EPCs: Endothelial Progenitor cells; PBMCs: Peripheral blood mononuclear cells.

\section{ABOUT AUTHORS}

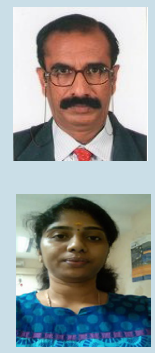

R. Raveendran: Is an MD in Pharmacology and is currently a professor of pharmacology in JIPMER, Pondicherry. He has more than 30 years of research and undergraduate and postgraduate teaching experience and has published more than 40 research papers apart from one book and a few software packages for computer assisted learning of pharmacology. His current interests are plant products and computer assisted learning. His specialization is in the area of standardization of herbal raw materials/medicinal plants, toxicological, pharmacological and pharmacokinetic studies.

Rupadevi Muthaian: Is a Ph.D. student in Department of Pharmacology, Jawaharlal Institute of Postgraduate Medical Education and Research (JIPMER), Pondicherry, INDIA. She has completed M.Sc. in the subject of Environmental Toxicology at University of Madras. She is pursuing her Ph.D. and also working as a Senior Research Fellow-Direct funded by Council of Scientific and Industrial Research, Government of India.

\section{REFERENCES}

1. Zheng $Y$, He M, Congdon N. The worldwide epidemic of diabetic retinopathy Indian J Ophthalmol. 2012:60(5):428-31.

2. Curtis T, Gardiner T, Stitt A. Microvascular lesions of diabetic retinopathy: clues towards understanding pathogenesis?. Eye. 2009;23(7):1496-508.

3. Sharma N, Gardiner T, Archer D. A morphologic and autoradiographic study of cell death and regeneration in the retinal microvasculature of normal and diabetic rats. Am J Ophthalmol. 1985;100(1):51-60.

4. Linskens MH, Harley CB, West MD, Campisi J, Hayflick L. Replicative senescence and cell death. Science. 1995;267(5194):13

5. Bhatwadekar AD, Glenn JV, Curtis TM, Grant MB, Stitt AW, Gardiner TA. Retinal endothelial cell apoptosis stimulates recruitment of endothelial progenitor cells. Invest Ophthalmol Vis Sci. 2009;50(10):4967-73.

6. Medina RJ, O'Neill CL, Humphreys MW, Gardiner TA, Stitt AW. Outgrowth endothelial cells: characterization and their potential for reversing ischemic retinopathy. Invest Ophthalmol Vis Sci. 2010;51(11):5906-13.

7. Kusuyama T, Omura T, Nishiya D, Enomoto S, Matsumoto R, Takeuchi K. Effects of treatment for diabetes mellitus on circulating vascular progenitor cells. J Pharmacol Sci. 2006;102(1):96-102.

8. Loomans CJ, de Koning EJ, Staal FJ, Rookmaaker MB, Verseyden C, de Boer HC. Endothelial progenitor cell dysfunction a novel concept in the pathogenesis of vascular complications of type 1 diabetes. Diabetes. 2004;53(1):195-9.
9. Grant MB, Caballero S, Brown GA, Guthrie SM, Mames RN, Vaught T. The contribution of adult hematopoietic stem cells to retinal neovascularization. Adv Exp Med Biol. 2003;522:37-45.

10. Raffi S, Lyden D. Therapeutic stem and progenitor cell transplantation for organ vascularization and regeneration. Nature Med. 2003;9(6):702-12.

11. Yoder MC, Ingram DA. Endothelial progenitor cell: ongoing controversy for defining these cells and their role in neoangiogenesis in the murine system. Curr Opin Hematol. 2009a;16(4):269-73

12. Shi Q, Rafii S, Wu MH, Wijelath ES, Yu C, Ishida A. Evidence for circulating bone marrow-derived endothelial cells. Blood. 1998;92(2):362-7.

13. Ingram DA, Mead LE, Tanaka H, Meade V, Fonoglio A, Mortell K. Identification of a novel hierarchy of endothelial progenitor cells using human peripheral and umbilical cord blood. Blood. 2004;104(9):2752-60.

14. Ingram DA, Mead LE, Moore DB, Woodard W, Fenoglio A, Yoder MC. Vessel wall-derived endothelial cells rapidly proliferate because they contain a complete hierarchy of endothelial progenitor cells.Blood. 2005b;105(7): 2783-6.

15. van Ark J, Moser J, Lexis C, Bekkema F, Pop I, van der Horst I. Type 2 diabetes mellitus is associated with an imbalance in circulating endothelial and smooth muscle progenitor cell numbers. Diabetologia. 2012;55(44):2501-12

16. Tan K, Lessieur E, Cutler A, Nerone P, Vasanji A, Asosingh K. Impaired function 
of circulating CD34+CD45-cells in patients with proliferative diabetic retinopathy. Exp Eye Res. 2010;91(2):229-37.

17. Lombardo MF, lacopino P, Cuzzola M, Spiniello E, Garreffa C, Ferrelli F. Type 2 diabetes mellitus impairs the maturation of endothelial progenitor cells and increases the number of circulating endothelial cells in peripheral blood. Cytometry. A 2012;81(10):856-64

18. Fadini GP, Sartore S, Baesso I, Lenzi M, Agostini C, Tiengo A. Endothelial progenitor cells and the diabetic paradox. Diabetes Care. 2006;29(3):714-6.

19. Cogan DG, Toussaint D, Kuwabara T. Retinal vascular patterns. IV. Diabetic retinopathy. Arch Ophthalmol. 1961;66(3):366-78.

20. Peichev M, Naiyer AJ, Pereira D, Zhu Z, Lane WJ, Williams M. Expression of VEGFR-2 and AC133 by circulating human CD341 cells identifies a population of functional endothelial precursors. Blood. 2000;95(3):952-8.

21. Hamed S, Brenner B, Roguin A. Nitric oxide: a key factor behind the dysfunctionality of endothelial progenitor cells in diabetes mellitus type-2. Cardiovas Res. 2011;91(1):9-15.

22. Bahlmann FH, De Groot K, Spandau JM, Landry AL, Hertel B, Duckert T. Erythropoietin regulates endothelial progenitor cells. Blood. 2004;103(3):921-6.

23. Dimmeler S, Aicher A, Vasa M, Mildner-Rihm C, Adler K, Tiemann M. HMG-CoA reductase inhibitors (statins) increase endothelial progenitor cells via the PI 3-kinase/Akt pathway. J Clin Invest. 2001;108(3):391-7.

24. Fulton D, Gratton JP, McCabe TJ, Fontana J, Fujio Y, Walsh K. Regulation of endothelium-derived nitric oxide production by the protein kinase Akt. Nature. 1999;399(6736):597-601.

25. Aicher A, Heeschen C, Mildner-Rihm C, Urbich C, Ihling C, Technau-Ihling K.
Essential role of endothelial nitric oxide synthase for mobilization of stem and progenitor cells. Nat Med. 2003;9(11):1370-6.

26. Fadini GP, Sartore S, Agostini C, Avogaro A. Significance of endothelial progenitor cells in subjects with diabetes. Diabetes Care. 2007;30(5):1305-13.

27. Humpert PM, Neuwirth R, Battista MJ, Voronko O, von Eynatten M, Konrade I. SDF-1 genotype influences insulin-dependent mobilization of adult progenitor cells in type 2 diabetes. Diabetes Care. 2005;28(4):934-6.

28. Francis S. Endothelial progenitor cells and coronary artery disease. Heart. 2004;90(6):591-2.

29. Si YF, Wang J, Guan J, Li Z, Sheng Y, Zhao J. Treatment with hydrogen sulfide alleviates streptozotocin-induced diabetic retinopathy in rats. $\mathrm{Br} \mathrm{J}$ Pharmacol. 2013;169(3):619-31.

30. Kumar B, Gupta SK, Srinivasan BP, Nag TC, Srivastava S, Rohit S. Hesperetin rescues retinal oxidative stess, neuroinflammtion and apoptosis in diabetic rats. Microvasc Res. 2013;87:65-74.

31. Izumi N, Nagaoka T, Mori F, Sato E, Takahashi A, Yoshida A. Relation between plasma nitric oxide levels and diabetic retinopathy. Jpn J Ophthalmol. 2006; 50(5):465-8.

32. Takeda M, Mori F, Yoshida A, Takamiya A, Nakagomi S, Sato E. Constitutive nitric oxide synthase is associated with retinal vascular permeability in early diabetic rats. Diabetologia. 2001;44(8):1043-50.

33. Brunner S, Schernthaner G, Satler M, Elhenicky M, Hoellerl F, SchmidKubista KE. Correlation of different circulating endothelial progenitor cells to stages of diabetic retinopathy: first in vivo data. Invest Ophthalmol Vis Sci. 2009;50(1):392-8. 